\title{
EFEITO DO CARREGAMENTO NO COMPRIMENTO DE SATURAÇÃO DE TRINCAS DE FADIGA PRODUZIDAS POR COMPRESSÃO NO AÇO API $5 \mathrm{~L}$ X60 *
}

\author{
Thinnie Hahn dos Santos ${ }^{1}$ \\ Rômulo F. Guerra Rigoni \\ Carlos Eduardo Fortis Kwietniewski ${ }^{3}$
}

\section{Resumo}

O aço API 5L X60 é empregado na fabricação de dutos submarinos para a produção de óleo e gás. Com a ajuda de métodos de inspeção e estudos de mecânica da fratura é possível avaliar a severidade dos defeitos existentes, prever a falha dos componentes e tomar as devidas providências para evitar acidentes que podem levar a danos ambientais, perda de vidas e prejuízos financeiros. Com foco na redução do efeito do histórico de carregamento, avalia-se uma técnica alternativa de pré-trincamento por fadiga para a obtenção das curvas de crescimento de trinca por fadiga. Esta técnica permite a nucleação de trincas em carregamento cíclico compressivo, isentas de tensões residuais compressivas, que mascaram os resultados na determinação do limiar de propagação de trincas. Neste trabalho, foram utilizados corpos de prova do tipo $\mathrm{C}(\mathrm{T})$ para a nucleação das pré-trincas de fadiga. Foi avaliada a influência das características do carregamento, como o nível da força aplicada e a razão de carregamento no comprimento de saturação das trincas produzidas, a fim de se obter avanços no estabelecimento dessa metodologia. Com um carregamento mais intenso, o comprimento de saturação de trinca foi maior. Além disso, a diferença de comprimento entre o centro e as superfícies do corpo de prova se torna mais acentuada. $O$ comprimento de saturação de trinca é menor que o raio da zona plástica e maior que a região máxima governada por tensões residuais trativas. Para carregamentos menos severos, a trinca cresce de maneira mais uniforme e alcança comprimentos de saturação de trinca menores. A razão de carregamento não interfere significativamente no comprimento de saturação de trinca.

Palavras-chave: Mecânica da fratura; Pré-trincamento; Fadiga em compressão.

\section{EFFECTS OF LOADING ON THE SATURATION CRACK LENGTH OF COMPRESSIVE PRECRACKED SPECIMENS OF API 5L X60 STEEL}

\section{Abstract}

The API 5L X60 steel is used in the manufacture of submarine pipelines for oil and gas. With the help of inspection methods and fracture mechanics studies, it"s possible to assess the severity of existing defects, predict component failure and take appropriate action to prevent accidents that could lead to environmental damage, loss of life and financial losses. In order to minimize effects due to load history, this work evaluates an alternative to the traditional pre-cracking of specimens used to determine fatigue crack growth curves. This technique allows the nucleation of cracks in compressive cyclic loading, free of compressive residual stresses, which influence the results in determining the crack growth threshold. In this work, specimens of type $\mathrm{C}(\mathrm{T})$ were used for the nucleation of fatigue pre-cracks. In order to obtain improvements in establishing this methodology, the influence of loading parameters were evaluated - such as the level of the applied force and the load ratio - in the saturation crack length. With a more intense load, crack saturation length increases, and the difference in length between the center and the specimen surfaces becomes more pronounced. The saturation crack length is smaller than the 
radius of the plastic zone, but larger than the zone governed by tensile residual stresses. For less severe load, the crack reaches shorter saturation crack lengths, and grows more evenly. The load ratio does not influence the crack length saturation. Keywords: Fracture mechanics; Pre-cracking; Compressive fatigue.

1 Engenheira Metalúrgica, Mestranda, Laboratório de Metalurgia Física (LAMEF) PPGE3M/UFRGS, Universidade Federal do Rio Grande do Sul, Porto Alegre, RS, Brasil.

2 Engenheiro Metalúrgico, Mestrando, Laboratório de Metalurgia Física (LAMEF) PPGE3M/UFRGS, Universidade Federal do Rio Grande do Sul, Porto Alegre, RS, Brasil.

3 Engenheiro Metalúrgico, Professor Doutor, Laboratório de Metalurgia Física (LAMEF) PPGE3M/UFRGS, Universidade Federal do Rio Grande do Sul, Porto Alegre, RS, Brasil. 


\section{INTRODUÇÃO}

$\mathrm{Na}$ indústria do óleo e gás, tubulações estão suscetíveis a defeitos oriundos dos processos de fabricação, instalação ou operação. O possível crescimento e eventual falha deste tipo de componente pode acarretar riscos ambientais e severas perdas econômicas, o que justifica um controle das estruturas por meio de análises de integridade estrutural, além de pesquisa a respeito do comportamento do material com uma abordagem da mecânica da fratura.

Nos dutos submarinos, variações na pressão interna, ondas e correntes marítimas geram tensões cíclicas que estarão sempre presentes e, por isso, o dano por fadiga é um fato que precisa ser considerado. Com o auxílio dos métodos de inspeção e o emprego da mecânica da fratura, é possível avaliar a severidade dos defeitos existentes, prever a falha dos componentes e tomar as devidas providências para evitar acidentes que podem levar a danos ambientais, perda de vidas e prejuízos financeiros. A avaliação adequada permite determinar quais defeitos precisam ser reparados, evitando paradas desnecessárias, além de permitir a maximização da vida útil do componente.

As curvas de fadiga utilizadas para a determinação do comportamento de defeitos em fadiga são determinadas pela metodologia descrita na norma ASTM E647 [1]. A partir destas curvas é possível fazer a previsão da vida remanescente do material. Entretanto a metodologia estabelecida não contempla aspectos que influenciam fortemente na determinação do limiar de propagação - uma condição limite de nãopropagação das trincas.

Para tais estudos, o ensaio conta com uma etapa de pré-trincamento, nucleando uma trinca inicial para que se possa avaliar o material na condição de um defeito severo. Esta etapa de nucleação é feita em fadiga, com tensão puramente trativa, entretanto, este carregamento também gera plastificação na ponta da trinca, e o retorno elástico do material adjacente também faz com que uma zona à frente da trinca sofra esforços compressivos, que são negligenciados nas etapas posteriores. Em ensaios de taxa de propagação de trinca, a tensão residual compressiva provoca efeito de fechamento de trinca, o que pode alterar significativamente o resultado do limiar de propagação para um valor menos conservador.

Outras metodologias vêm sendo propostas de forma a atenuar estas influências. Uma delas tem o propósito de evitar a formação de tensões residuais compressivas, durante o pré-trincamento por fadiga, que têm o potencial de diminuir a tensão efetiva aplicada, produzindo assim resultados não conservadores. Este método consiste no pré-trincamento por fadiga do corpo de prova por um carregamento cíclico compressivo. Isto evita os efeitos do fenômeno de fechamento de trinca induzido por plasticidade, garantindo valores mais realistas quando comparados ao método convencional descrito na norma ASTM E647.

O presente trabalho tem como principal objetivo avaliar a influência das características do carregamento no comprimento de saturação da trinca obtida por compressão, a fim de estabelecer avanços no estabelecimento de uma metodologia para o pré-trincamento em compressão. A literatura aponta que, com um carregamento mais intenso, a trinca propague por uma distância maior até deixar de 
sofrer influência da região governada por tensões residuais trativas, que são formadas no primeiro ciclo de fadiga [2, 3, 4, 5]. Também tem-se como objetivo avaliar a frente de propagação da trinca.

Foi observado que as pré-trincas obtidas pelo carregamento cíclico compressivo não sofrem o fenômeno de fechamento de trinca induzido por plasticidade, minimizando incertezas na medição de taxas de crescimento muito baixas [6, 7].

O processo de pré-trincamento por compressão está esquematizado na Figura 1. Na Figura 1(b), tem-se o tipo de carregamento utilizado e o respectivo estado de deformação em relação à tensão aplicada. Os estados (1) e (2) no diagrama de carga correspondem aos estados de carregado (1) e descarregado (2) no diagrama tensão-deformação e nos outros esquemas da figura. $O$ primeiro ciclo de carregamento compressivo aplicado deforma o material na região próxima ao entalhe, formando a zona plástica compressiva, cuja dimensão é dada pelo raio rp. Ao descarregar, o retorno elástico gera um campo de tensões residuais trativas (zona cujo raio é $r \Delta$ ) devido ao material adjacente, representado pela chamada zona plástica monotônica trativa (ver Figura 1(c)). A Figura 1(d) mostra o esquema da distribuição de tensões na região próxima ao entalhe nos estados de carregado e descarregado. As cargas cíclicas subsequentes provocam a nucleação e propagação da trinca por fadiga.

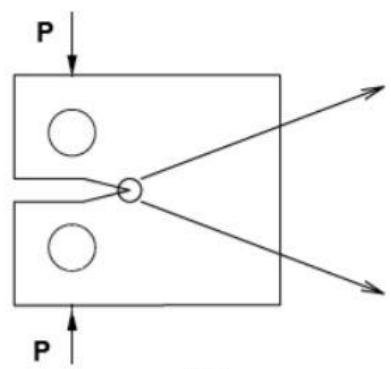

(a)

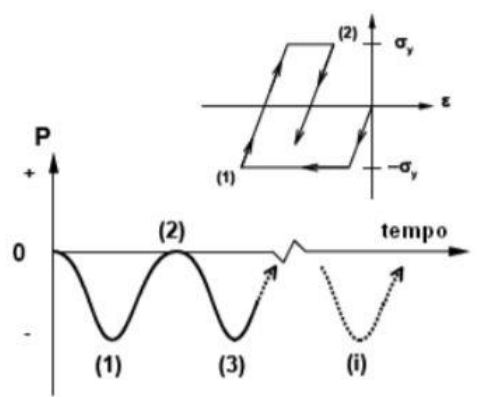

(b)

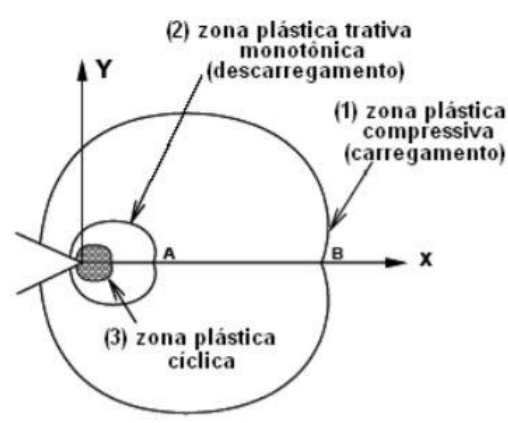

(c)

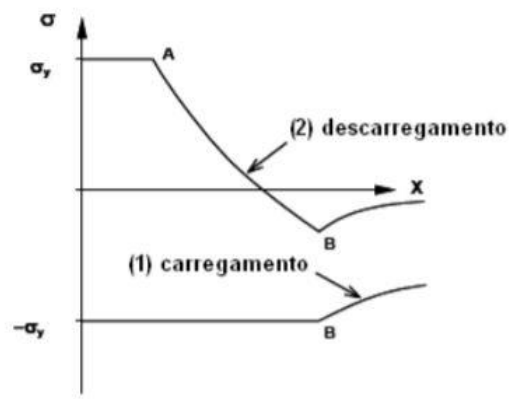

(d)

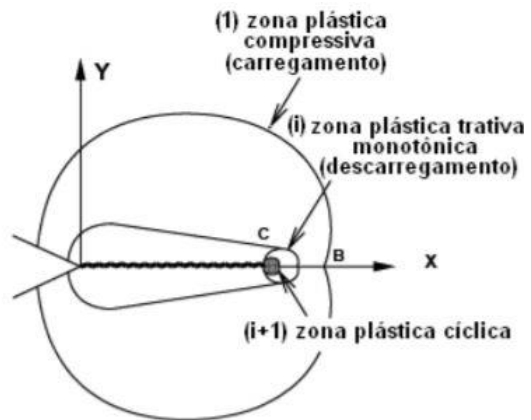

(e)

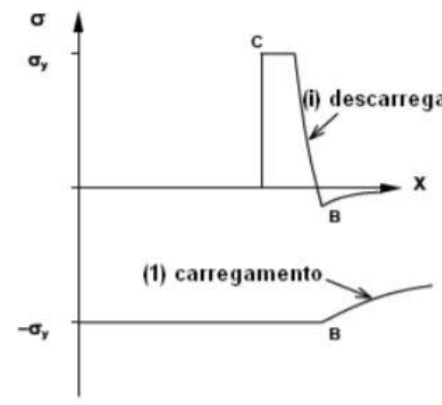

(f)

Figura 1. Representação esquemática do processo de pré-trincamento compressivo. FONTE: Ádaptado de JAMES; FORTH; NEWMAN, 2005 [8].

Durante o carregamento compressivo, as faces da trinca já nucleada se encostam, e a carga é transmitida no corpo de prova como se a trinca não existisse. Por isso, a zona plástica compressiva permanece inalterada nos ciclos subsequentes mesmo na presença da trinca, como demonstrado na Figura 1(e).

A propagação da trinca se dá através do campo dominado pelas tensões residuais trativas. Assim, estas são aliviadas conforme a trinca propaga e o tamanho da zona 
plástica cíclica fica reduzido. À medida que o campo dominado pelas tensões residuais trativas diminui, a força motriz para a propagação da trinca também diminui, até que essa atinja o limiar de propagação e pare de crescer, mesmo que o carregamento cíclico compressivo continue sendo aplicado [5, 8, 9].

A distância máxima que a trinca cresce até sofrer estagnação natural é denominada de comprimento de saturação de trinca $\left(a^{*}\right)$ e está relacionada com o maior raio da zona plástica, correspondente à primeira carga compressiva aplicada.

Neste trabalho a atuação deste fenômeno em um aço de comum utilização em dutos e abordada, buscando quantificar a influência de parâmetros de carregamento e possibilitar uma metodologia que permita-se pré-trincas em corpos de prova de escala laboratorial sem efeito das tensões residuais desta etapa.

\section{MATERIAIS E MÉTODOS}

\subsection{Caracterização do Material}

O material empregado neste trabalho é o aço API 5L X60, utilizado na fabricação de dutos. Um corpo de prova foi retirado de um segmento de duto para se determinar a composição química e as propriedades mecânicas do mesmo, com análise metalográfica, ensaio de dureza e ensaio de tração.

A composição química do material foi determinada através de espectrometria de emissão ótica no modelo $02 \mathrm{ION}$ da marca Bruker. O resultado obtido está apresentado na Tabela 1, juntamente com a composição estabelecida pela norma API 5L [10].

Tabela 1 Média dos resultados da análise química em comparação à norma Porcentagem em massa

\begin{tabular}{cccccc}
\hline Elemento & C [\%] & Mn [\%] & $\mathbf{P ~ [ \% ] ~}$ & $\mathbf{S ~ [ \% ] ~}$ & $\begin{array}{c}\mathbf{N b}+\mathbf{T i}+\mathbf{V} \\
{[\%]}\end{array}$ \\
\hline Média & 0.131 & 1,055 & 0,041 & $<0,01$ & 0,134 \\
\hline API 2012 & $<0,28$ & $<1,4$ & $<0,03$ & $<0,03$ & $\leq 0,15$ \\
\hline
\end{tabular}

A microestrutura do material é formada por ferrita e perlita em bandas, e está apresentada na Figura 2, conforme esperado para o material.

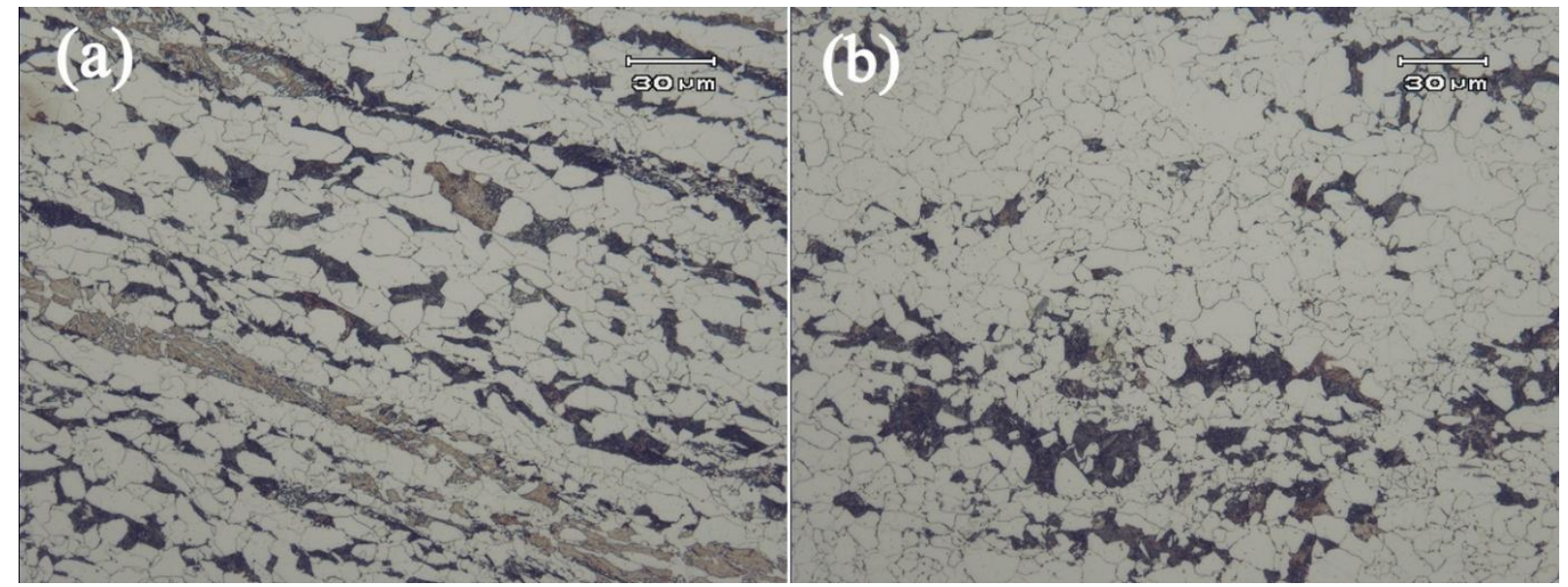


Figura 2. Microestrutura do material utilizado no sentido (a) longitudinal do tubo e (b) transversal do tubo.

Os resultados de dureza estão representados na Tabela 2 e estão dentro da faixa estabelecida pela norma API 5L [10].

Tabela 2. Dureza do material

\begin{tabular}{ccccccc}
\hline & Ensaio 1 & Ensaio 2 & Ensaio 3 & Ensaio 4 & Ensaio 5 & Média \\
\hline $\begin{array}{c}\text { Dure } \\
\text { za (HB) }\end{array}$ & 187 & 187 & 207 & 187 & 207 & 195 \\
\hline
\end{tabular}

O ensaio de tração foi realizado em uma máquina servo-hidráulica MTS, modelo 810 , seguindo as recomendações da norma ASTM A370 [11] e os resultados estão apresentados na Tabela 3 . Os valores de tensão de escoamento e de resistência à tração foram obtidos a partir da média de três ensaios.

Tabela 3. Resultados obtidos no ensaio de tração

\begin{tabular}{ccccc}
\hline & Ensaio 1 & Ensaio 2 & Ensaio 3 & Média \\
\hline $\begin{array}{c}\text { Tensão de } \\
\text { Escoamento [MPa] }\end{array}$ & 471 & 486 & 488 & 481 \\
\hline Resistência à Tração & 620 & 615 & 619 & 618 \\
[MPa] & & & & \\
\hline
\end{tabular}

\section{2 corpos de prova - pré trincamento}

Os corpos de prova empregados nos testes de pré-trincamento foram retirados de um segmento de duto de $520 \mathrm{~mm}$ de diâmetro externo, espessura de $16 \mathrm{~mm}$ e comprimento de $320 \mathrm{~mm}$. A orientação dos corpos de prova retirados do tubo é denominada C-L, segundo a norma ASTM E399 [12] e está representada na Figura 3. Nesta orientação, a propagação da trinca no corpo de prova simula o crescimento de uma trinca na direção longitudinal do tubo. A Figura 4 apresenta as dimensões do corpo de prova utilizado nos ensaios de pré-trincamento.

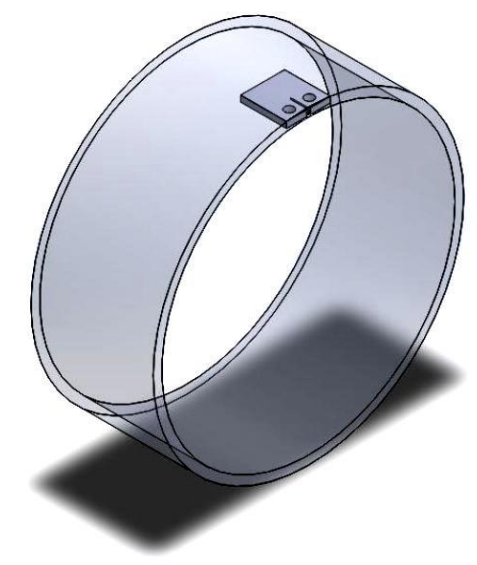

Figura 3. Orientação dos corpos de prova no tubo.
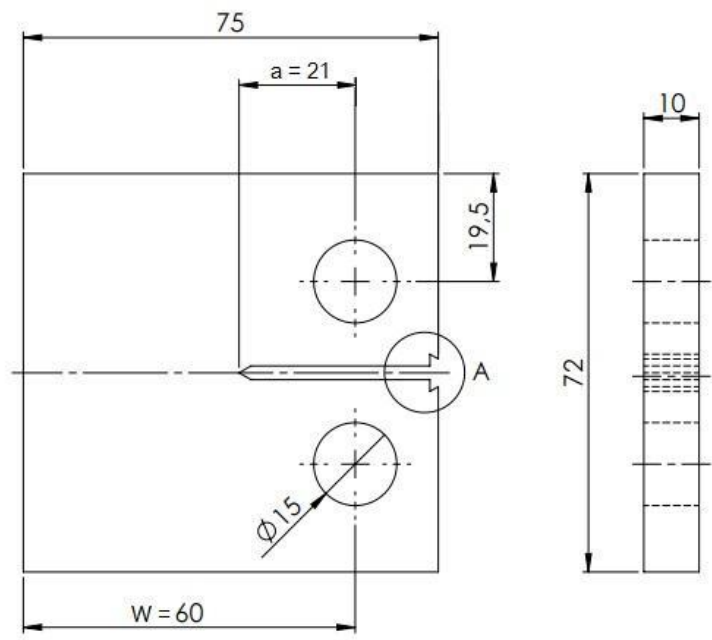

Figura 4. Dimensões do corpo de prova $\mathrm{C}(\mathrm{T})$ utilizado.

Após os ensaios de caracterização, os corpos de prova foram submetidos ao ensaio de pré-trincamento em uma máquina servo-hidráulica MTS, modelo 810. Os 
parâmetros avaliados foram o Kmin aplicado, a razão de carregamento(R) e o tamanho de saturação de trinca, que governam a formação das zonas plástica e governada pelas tensões residuais.

\subsection{Medição do tamanho de trinca}

Para se determinar o tamanho da trinca e averiguar a estagnação natural da mesma, foram utilizadas quatro técnicas comuns na área de mecânica da fratura. São eles: queda de potencial, Compliance, Crack Gage Kyowa modelo KV-5C e análise visual através do programa ImageJ.

A técnica da queda de potencial baseia-se na medição da variação de potencial elétrico causada no corpo de prova devido a uma descontinuidade, aplicando-se uma corrente constante. Com o crescimento da trinca, a resistência elétrica do corpo de prova aumenta e registra-se uma queda de potencial. Ela não se mostrou apropriada, uma vez que a abertura da trinca nucleada em compressão não é suficiente para impedir a passagem de corrente.

O método de Compliance utiliza um sensor do tipo clip gage MTS, que é acoplado ao corpo de prova e integrado ao sistema, medindo o tamanho da trinca através da abertura da boca da do entalhe (CMOD), conforme recomendações da norma ASTM E399 [12]. A técnica também não foi efetiva, uma vez que também depende do fato de a trinca estar aberta em tração.

O Crack Gage é constituído por uma série de filamentos de resistência elétrica, dispostos a uma distância de $0,1 \mathrm{~mm}$ um do outro. Esta rede de filamentos é colada na superfície lateral dos corpos de prova na área de propagação da trinca, de modo que o avanço dessa cause rupturas sequenciais dos filamentos do Crack Gage. Cada ruptura gera uma diferença de potencial elétrico, que é medida e relacionada com o tamanho da trinca ao longo do tempo. Porém, a abertura da trinca nucleada no carregamento compressivo não foi suficiente para romper os filamentos do crack gage, não sendo possível detectar o crescimento.

A análise visual do comprimento da pré-trinca foi realizada através de uma imagem da trinca obtida em microscópio ótico e, posteriormente, medida no programa ImageJ, conforme o exemplo da figura Figura 5. 


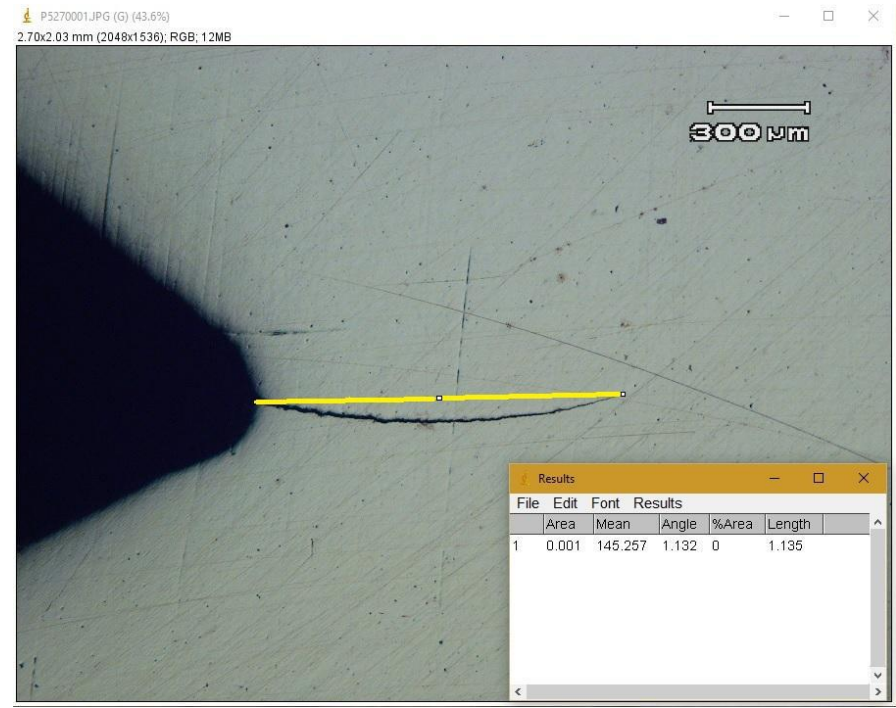

Figura 5. Medição da trinca através do programa ImageJ.

De todos os métodos utilizados para a medição das trincas, o único capaz de fornecer resultados coerentes foi a análise visual através do programa ImageJ, apesar da necessidade de interrupções no ensaio para se fazer uma medição. Após o término do ensaio, de acordo com o critério de parada estabelecido, foram produzidas imagens que, posteriormente, foram analisadas.

Estabeleceu-se que os ensaios terminariam quando se alcançasse a marca de 5000 000 ciclos, ou a/W=0,5 (o que tivesse acontecido primeiro). O comprimento de $a / w=0,5$, usado em ensaios de tenacidade, foi escolhido como um dos critérios de parada para evitar a nucleação de trincas muito longas. Trincas maiores possuem pouca aplicação na prática.

Após o pré-trincamento, os corpos de prova foram submetidos a um carregamento cíclico trativo até o rompimento. Após a ruptura, foi feita uma análise fractográfica para avaliar a frente de propagação da trinca e o micromecanismo de fratura e para relacioná-los com o estado de tensões na ponta da trinca.

\subsection{Análise Fractográfica}

Para se observar a frente de propagação da trinca, foram obtidas fotos da superfície de fratura dos corpos de prova utilizados no carregamento compressivo. Através desta análise, é possível verificar a conformidade com os desvios tolerados pela norma ASTM E647 [1].

\section{RESULTADOS E DISCUSSÃO}

\subsection{Medição das trincas}

Os comprimentos de trinca obtidos encontram-se na Tabela 7.

Tabela 7. Título da tabela sem ponto final

\begin{tabular}{ccccccc}
\hline $\begin{array}{c}\text { Corpo de } \\
\text { prova }\end{array}$ & $\begin{array}{c}\text { Carga } \\
\text { Mínima [kN] }\end{array}$ & $\begin{array}{c}\text { Razão de } \\
\text { carregamento }\end{array}$ & $\begin{array}{c}\text { KMín } \\
{[\mathrm{MPa} . /]}\end{array}$ & $\begin{array}{c}\mathbf{a}^{*} \text { lado A } \\
{[\mathrm{mm}]}\end{array}$ & $\begin{array}{c}\text { a* lado B } \\
{[\mathrm{mm}]}\end{array}$ & $\begin{array}{c}\text { Critério de } \\
\text { Parada }\end{array}$ \\
\hline CP 1 & $-13,5$ & 20 & 35,2 & 0,401 & 0,942 & $5 \times 10^{6}$ ciclos \\
\hline
\end{tabular}




\begin{tabular}{ccccccc}
\hline CP 2 $^{*}$ & $-13,5$ & 100 & 35,2 & 0,437 & 5,961 & $5 \times 10^{6}$ ciclos \\
\hline CP 3 $^{*}$ & $-18,0$ & 20 & 47,0 & 1,156 & 1,671 & $5 \times 10^{6}$ ciclos \\
\hline CP 4 & $-18,0$ & 100 & 47,0 & 1,322 & 4,627 & $5 \times 10^{6}$ ciclos \\
\hline CP 5 & $-18,0$ & 100 & 47,0 & 1,279 & 2,553 & $5 \times 10^{6}$ ciclos \\
\hline CP 6 & $-20,0$ & 100 & 52,2 & 1,403 & 3,229 & $5 \times 10^{6}$ ciclos \\
\hline CP 7 & $-30,0$ & 100 & 78,3 & 6,671 & 16,649 & $5 \times 10^{6}$ ciclos \\
\hline CP 8 & $-40,0$ & 100 & 104,4 & 8,65 & 10,247 & $(\mathrm{a} / \mathrm{W})=0,5$ \\
\hline
\end{tabular}

${ }^{*}$ Resultados invalidados devido à diferença de comprimento entre as trincas.

Segundo a norma ASTM E647 [1], a diferença de comprimento de trinca entre os dois lados do corpo de prova não deve exceder $25 \%$ da espessura, ou seja, $2,5 \mathrm{~mm}$. Assim, todas as pré-trincas nucleadas encontram-se dentro da faixa admitida pela norma, com exceção dos CP2, CP4 e CP7.

A diferença de comprimento de trinca nos dois lados dos corpos de prova 2 e 4 é maior que o tolerado pela norma. Uma possível causa para a nucleação de trincas não uniformes é o deslocamento do dispositivo na máquina ou então, algum problema no momento da usinagem do corpo de prova que tenha feito com que os lados superior e inferior não tenham ficado paralelos. Os dois corpos de prova apresentaram marcas do dispositivo na parte superior e inferior do corpo de prova, como demonstrado na Figura 6, indicando que a carga foi aplicada mais severamente de um lado do que do outro, possivelmente levando ao crescimento não uniforme da trinca.

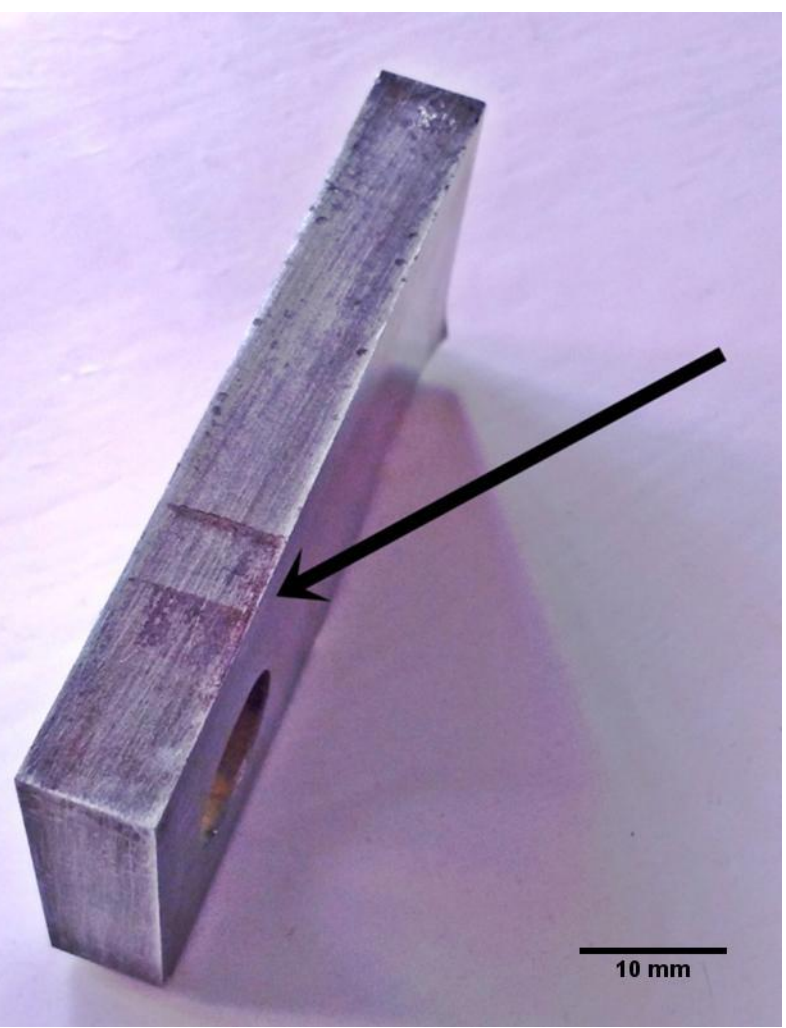

Figura 6. Marca do dispositivo no corpo de prova após pré-trincamento.

Além disso, o Corpo de Prova 7 apresentou nucleação de duas trincas no lado A, conforme mostra a Figura 7. Por isso, a diferença de tamanho de trinca entre o lado $\mathrm{A}$ e o lado B foi tão significativa. A nucleação da trinca no início do entalhe em $\mathrm{V}$ 
indica que deve-se usar um raio de concordância para que a trinca nucleie apenas no local correto.

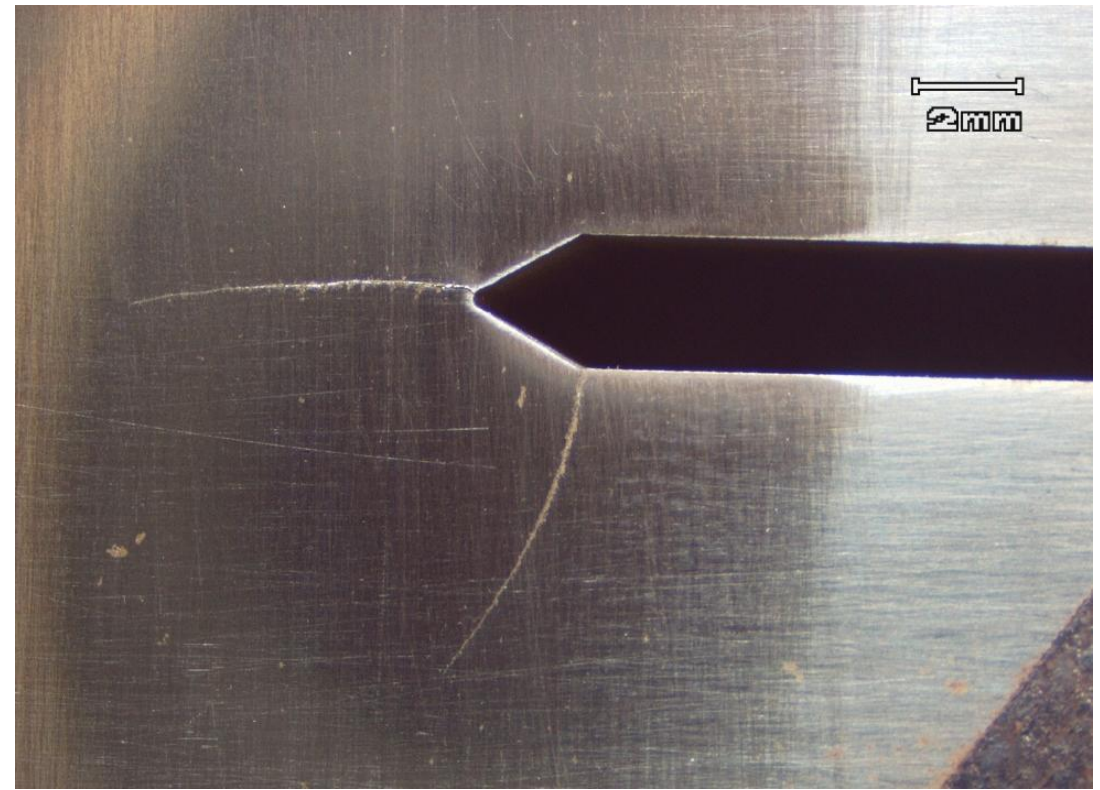

Figura 7. Trincas nucleadas em dois pontos diferentes do entalhe no CP7.

É importante ressaltar que o corpo de prova 8 atingiu um valor $\mathrm{a} / \mathrm{w}=0,5$ antes de atingir $5 \times 10^{6}$ ciclos e, portanto, não se considera que esta trinca tenha atingido a saturação.

A Figura 8 mostra o tamanho de saturação de trinca médio, $\mathrm{a}^{*}$, a partir dos dois lados do corpo de prova em função do fator de intensidade de tensões mínimo aplicado.

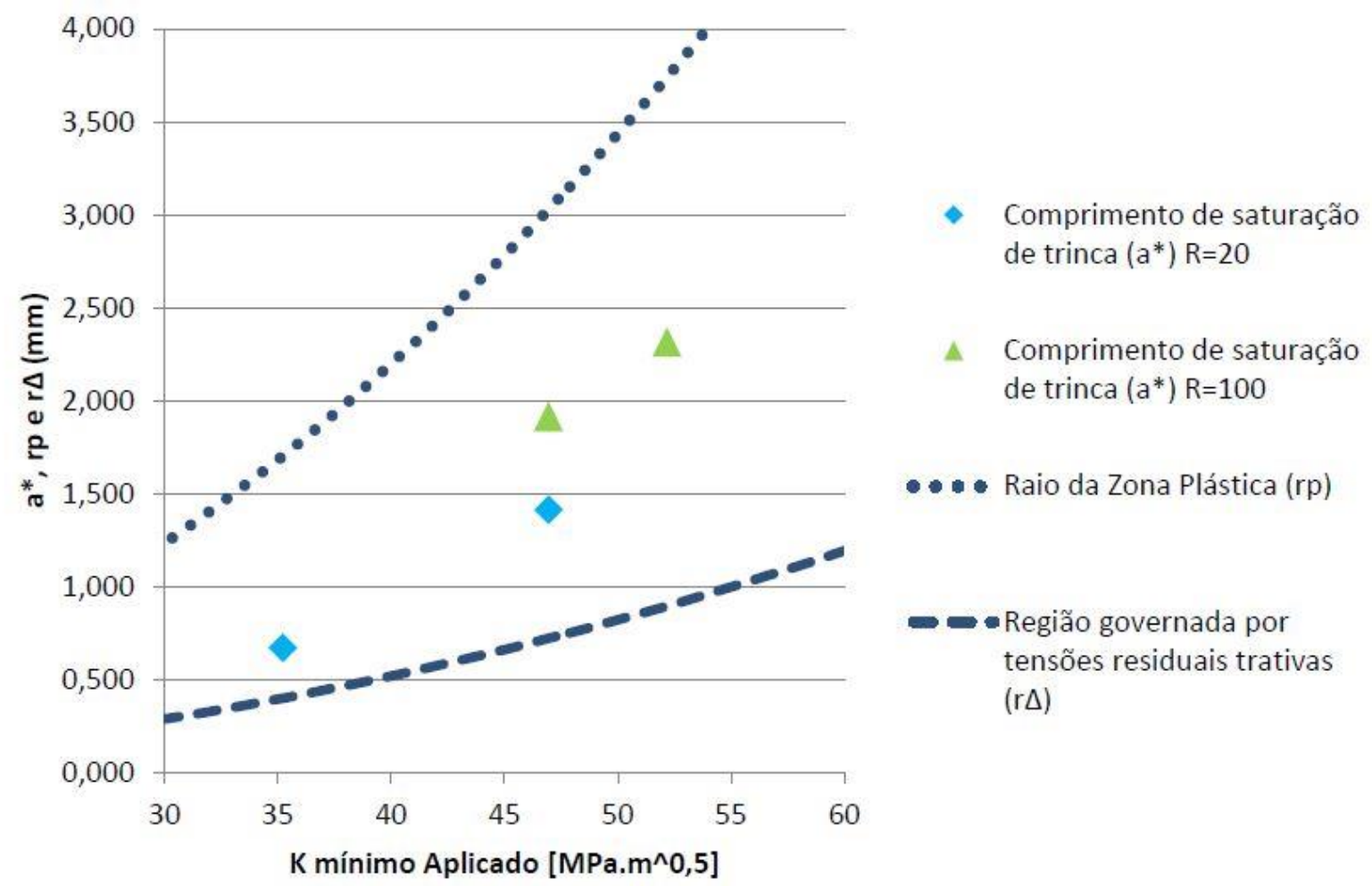

Figura 8. Comprimento de saturação de trinca, $a^{*}$, em função do valor de Kmín aplicado. 
É possível perceber que $a^{*}$ possui um valor que fica entre o tamanho da zona plástica compressiva $\left(r_{p}\right)$ e o tamanho máximo da região governada pelas tensões residuais trativas $\left(r_{\Delta}\right)$, conforme previsto pela literatura.

Além disso, o raio da zona plástica e o tamanho da região governada pelas tensões residuais trativas aumentam com o aumento da severidade do $K_{\text {mín }}$ aplicado e, consequentemente, 0 tamanho de saturação de trinca também aumenta. $O$ comprimento de saturação crítico observado por Suresh [13] para o aço SA 542 Classe 3, não foi observado para os valores de $K_{\text {min }}$ utilizados neste estudo.

Aumentando a razão de carregamento, para um mesmo valor de $\mathrm{K}_{\text {mín }}$ aplicado (mesmo valor de $P_{\min }$ ), não observou-se uma variação significativa no comprimento de saturação da trinca entre o CP3 e o CP5. De fato, é primeiro ciclo de carregamento compressivo que deforma 0 material plasticamente e dá origem às tensões residuais trativas. $O$ aumento de $R$, para um mesmo valor de $P_{\text {mín, afeta a }}$ tensão efetiva atuante, aumentando a taxa de propagação da trinca, mas não o seu comprimento de saturação.

Como os corpos de prova 2 e 4 apresentaram trincas fora do limite estabelecido pela norma, o corpo de prova 7 apresentou nucleação de duas trincas e o Corpo de Prova 8 não atingiu a saturação da trinca, estes foram desconsiderados na apresentação de resultados da Figura 8.

\subsection{Análise Fractográfica}

As superfícies de fratura estão apresentadas na Figura 9. É possível observar que a frente de propagação do CP1 e do CP3 foi mais uniforme e paralela ao entalhe, mostrando que essa não depende apenas da espessura do corpo de prova. Isto está de acordo com o observado por Pippan (1994), que demonstrou que a frente de propagação da trinca é mais uniforme para baixos valores de $\Delta \mathrm{K}$. Realmente, para os corpos de prova com maior $\Delta \mathrm{K}$ aplicado, a frente de propagação não foi tão uniforme, como pode-se observar no CP5 e CP6. 

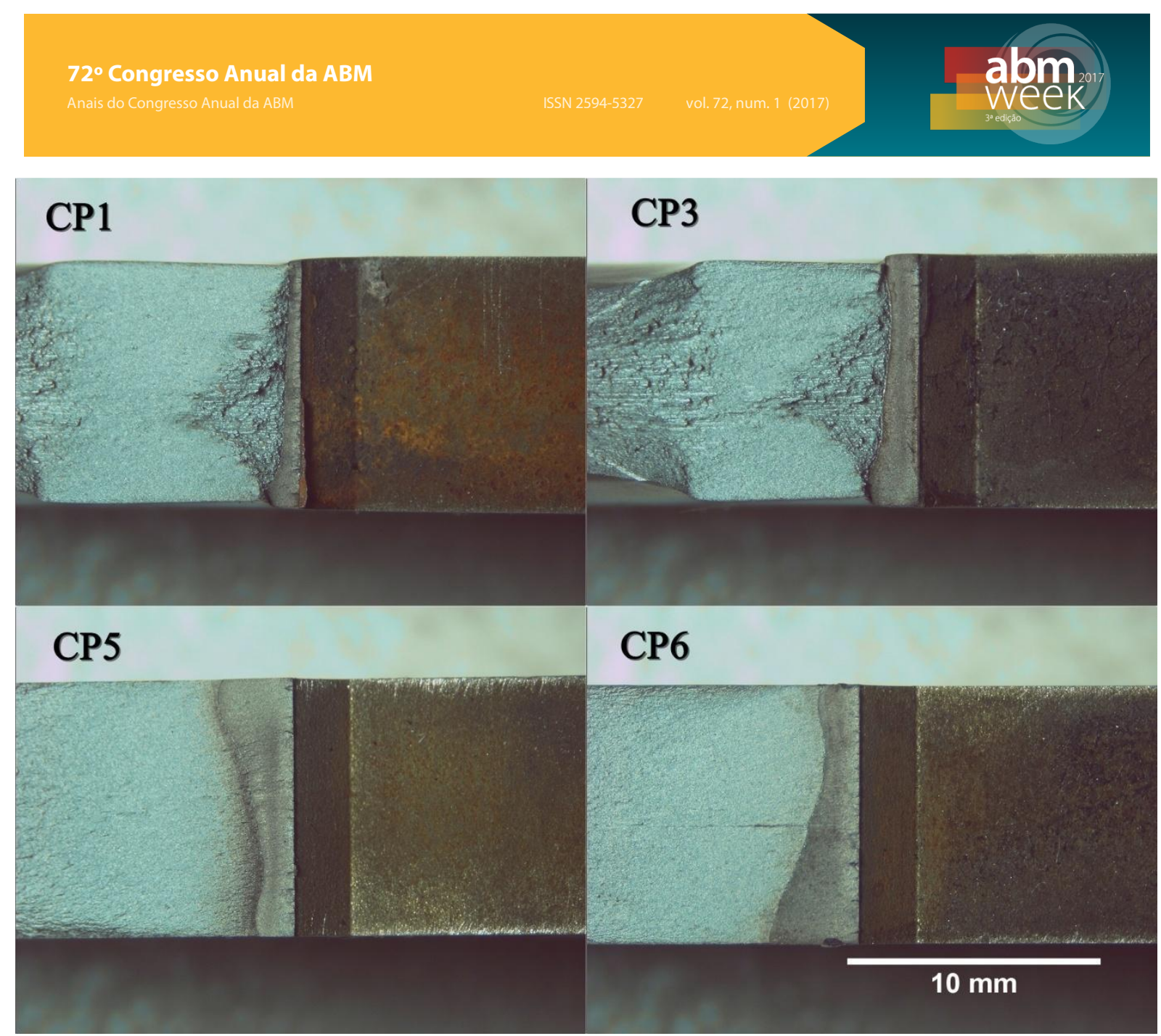

Figura 9. Superfícies de fratura das pré-trincas dos Corpos de Prova CP1, CP3, CP5 e CP6. Nos Corpos de Prova CP1 e CP3, a frente de propagação é mais paralela ao entalhe. Nos Corpos de Prova CP5 e CP6, a frente de propagação das trincas teve maior diferença de comprimento.

Ainda assim, é possível observar que a trinca propaga mais na região próxima à superfície do que no centro do corpo de prova. Este resultado está de acordo com os estudos feitos por Holm et al. [14]. Através de análises por elementos finitos, foi demonstrado que estado plano de deformações no centro do corpo de prova favorece o aumento do nível de fechamento de trinca, fazendo com que a trinca propague menos nessa região.

\section{CONCLUSÃO}

Através destas análises, pode-se observar algumas particularidades do prétrincamento compressivo, em especial para o caso do aço API 5L X60:

A técnica mais adequada para esta medição é a de inspeção visual, uma vez que as de queda de potencial, compliance e uso de crack gages possuem limitações baseadas na natureza da abertura da trinca e da tensão aplicada.

As trincas encontradas tiveram comportamento dentro do esperado quanto tamanho, se limitando entre o raio da zona plástica e o da governada por tensões residuais.

Enquanto o comprimento de saturação é dependente do raio da zona plástica, e consequentemente do $\mathrm{K}_{\min }$ aplicado, a razão de carregamento não apresentou grande influência. Entretanto, grandes razões aparentam implicar na nucleação de trincas secundárias. 


\section{REFERÊNCIAS}

1 ASTM. ASTM E647 Standard Test Method for Measurement of Fatigue Crack Growth Rates.

2 PIPPAN, R. The lenght and the shape of cracks under compression: the influence of notch geometry. Engineering Fracture Mechanics, p. 715-718, 1988.

3 PIPPAN, R. et al. The use of fatigue specimens precracked in compression for measuring threshold values and crack growth. Journal of Testing and Evaluation, v. 22, n. 2, p. 98-103, 1994.

4 KUHN, C. G. Comparação entre os métodos convencional e de pré trincamento compressivo para a obtenção de curvas de propagação de trinca no aço API 5L X60. Porto Alegre: UFRGS, 2011.

5 VELLOSO, I. P. D. S. Metodologia de Ensaio de Fadiga para a Região I da Curva da/dN-DK. Porto Alegre: UFRGS, 2009.

6 CHRISTMAN, T.; SURESH, S. Crack Initiation Under Far-Field Cyclic Compression and the Study of Short Fatigue Cracks. Engineering Fracture Mechanics, v. 23, n. $6,1986$.

7 HUBBARD, R. Crack growth under cyclic compression. Journal of Basic Engineering, v. 91, p. 625-631, 1969.

8 JAMES, M. A.; FORTH, S. C.; NEWMAN, J. A. Load History Effects Resulting from Compression Precracking. Journal of ASTM International, v. 2, n. 9, 2005.

9 RIGONI, R. F. G. Efeito do pré-trincamento compressivo e da razão de carregamento no limiar de propagação de trincas no aço API 5L X60. Porto Alegre: UFRGS, 2015.

10 AMERICAN PETROLEUM INSTITUTE. API 5L Specification for Line Pipe. Washington.

11 ASTM. ASTM A370 Standard Test Methods and Definitions for Mechanical Testing of Steel Products.

12 ASTM. ASTM E399 Standard Test Method for Linear-Elastic Plane-Strain Fracture Toughness Klc of Metallic Materials.

13 SURESH, S. Crack Initiation in Cyclic Compression and its Applications. Engineering Fracture Mechanics, v. 21, p. 10 páginas, 1985.

14 HOLM, D. K.; BLOM, A. F.; SURESH, S. Grouth of Cracks under Far-Field Cyclic compressive Loads: Numerical and Experimental Results. Engineering Fracture Mechanics, v. 23, n. 6, 1986. 